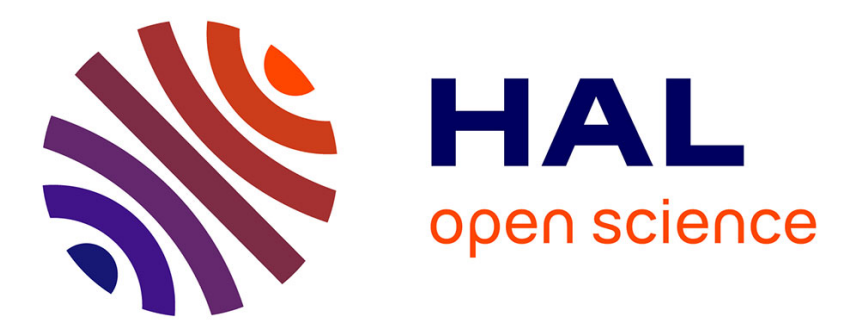

\title{
Correlation between the surface chemistry, the surface free energy and the adhesion of metallic coatings onto plasma-treated Poly(ether ether ketone)
}

\author{
David Gravis, Fabienne Poncin-Epaillard, Jean-François Coulon
}

\section{- To cite this version:}

David Gravis, Fabienne Poncin-Epaillard, Jean-François Coulon. Correlation between the surface chemistry, the surface free energy and the adhesion of metallic coatings onto plasma-treated Poly(ether ether ketone). Applied Surface Science, 2020, 501, pp.144242. 10.1016/j.apsusc.2019.144242 . hal03015947

\section{HAL Id: hal-03015947 \\ https://hal.science/hal-03015947}

Submitted on 20 Nov 2020

HAL is a multi-disciplinary open access archive for the deposit and dissemination of scientific research documents, whether they are published or not. The documents may come from teaching and research institutions in France or abroad, or from public or private research centers.
L'archive ouverte pluridisciplinaire HAL, est destinée au dépôt et à la diffusion de documents scientifiques de niveau recherche, publiés ou non, émanant des établissements d'enseignement et de recherche français ou étrangers, des laboratoires publics ou privés. 
Article type: Full paper

Correlation between the surface chemistry, the surface free energy and the adhesion of metallic coatings onto plasma-treatedPoly(ether ether ketone)

David Gravis, Fabienne Poncin-Epaillard, Jean-FrançoisCoulon**

David Gravis, Dr. Jean-François Coulon

jean-francois.coulon@ecam-rennes.fr

ECAM RENNES - Louis de Broglie, Campus de Ker Lann, CS 29 128, 35091 Rennes Cedex 09, France

Dr. Fabienne Poncin-Epaillard

Le Mans Université- CNRS n6283, Institut des Molécules et Matériaux du Mans Département Polymères, Colloïdes et Interfaces, Avenue Olivier Messiaen, 72085 Le Mans, France

Appl. Surf. Sci., 501, 144242 (2020)

\begin{abstract}
The effects of the surface modification of poly(ether ether ketone) (PEEK) by plasma treatment have been characterized by X-ray Photoelectron Spectroscopy and wettability
\end{abstract}


measurement, whilethe adhesion of metallic thin films grown by PVD has been assessed by the pull-off test. To investigate the role of the modified surface chemistry on the practical adhesion stress of aluminium thin films, two different plasma technologies were considered: (i) atmospheric pressure plasma and (ii) low pressure microwave plasma. Though on different scales, both of these plasmas under oxidative conditions induced a significant increase of the surface concentration of $\mathrm{C}=\mathrm{O}$ (ketones) and $\mathrm{COO}$ (esters and acidic) functional groups, while $\mathrm{C}-\mathrm{O}-\mathrm{C}$ (ether) groups remained constant. It is shown that after plasma functionalization, when the surface concentration of $\mathrm{C}=\mathrm{O}$ and $\mathrm{COO}$ are above a critical value, a strong correlation appears between the concentration of these polar groups, the wettability and the adhesion potential.

Keywords:adhesion; low pressure plasma (ECR); atmospheric pressure glow discharges (APGD);Poly(etheretherketone) (PEEK).

\section{Introduction}

Polymer composites are resilient and lightweight materials, attracting growing interest to replace metallic structures, in order to improve the energy efficiency of many means of transport.Several technical polymers are of particular interest, as for an example the polyimides, polycarbonates or polyaryletherketones. Yet, polymers are endowed with poor adhesiontowards many types of coating, from metallic to organic ones, and from solids to liquids. In order to enhance their adhesionpotential, the properties of the polymer surfaces are altered, by the modification of their topography, or by the modification of their chemistry. Recently, to stave off the toxicity and ecological drawbacks of usual wet chemistry, physical of gasphasetreatments are developed tosupersedewet processes, but highlight different new materials and surface properties enhancement challenges. 
Many studies show surface properties improvement thanks to plasma functionalization.For some of them, the effectiveness of this plasma treatment is studied in terms of contact angles of several liquids, and often in terms of the calculation of the surface free energy.[1-3]The study of the wettability can be sufficient to be able to predict the efficiency of the activation for several applications, such as paint spreading or printability for surfaces dyeing[4]. However,many other studies report the effect of the modification of the surface on the resulting adhesion properties as this is the main objectivewhen applied to different assemblies[5] or coatings[6,7]. In these literatures, the understandingof the modified surface chemistry is commonly achieved by X-ray Photoelectron Spectroscopy (XPS) analysis. Theresult of the functionalization which produces the change in wettability is henceobserved in terms of new chemical groups graftedon the surface, depending on the experimental conditions.

In our study, we were able to precisely adjust the functionalization mechanisms. This allowed monitoring a significant variation of the surface chemistry thus studying its effect onfirstly the wettability and secondly the adhesion potential. Thus, our study aims to highlight the active species formed on the surface and their evolution to discuss correlations betweenthe modified surface chemistry(XPS), the free energy andthe resulting practical adhesion potential (measured by the pull off test). Weinvestigated these relationships in the case of the adhesion improvement of a PVD coated metal thin film on PEEK substrates.

\section{Materials and methods}

\subsection{Materials and sample preparation}

Samples of Victrex ${ }^{\circledR} 450 \mathrm{G}$ PEEK were used for practical adhesion, wettability and surface chemistry characterization. To ensure minimal roughness before treatment, the samples 
were prepared by polishing their surface with a Struers LaboPol-5 polishing machine. Mean arithmetic roughness $\left(\mathrm{R}_{\mathrm{a}}\right)$ of $150 \pm 5 \mathrm{~nm}$ was attained thanks to the surface polishing. Then, the samples wereultrasonicated in ethanol for 30 min before treatment.

\subsection{Plasma surface treatments}

Two plasma treatments were used to compare their respective efficiencies and to verify the possible functionalization mechanisms they could have in common: an atmospheric pressure plasma treatment and a low pressure plasma treatment.Ageing of PEEK surfaces was already highlighted and characterized in our previous work[8]; for this current study, experimental precautions were thus taken to avoid surface properties degradation between plasma treatment and surface characterization due to surface ageing.

An atmospheric cold plasma treatment was applied using the Ultra-Light System arc plasma torch from $\mathrm{AcXys}^{\mathrm{TM}}$; in this system, the plasma (dry air, 4 bar) is sustained by a high voltage $(1.5 \mathrm{kV})$ and low frequency power $(100 \mathrm{kHz})$.Treatments were conducted by varying the scan speed (from 10 to $100 \mathrm{~mm} / \mathrm{s}$ ), the number of scans (1,2 and 3) and the surface - plasma distance $(2,3,4 \mathrm{~cm})$. Further information on the parametric study of this plasma apparatus can be found in our previous work[8].

Vacuum plasma treatments were conducted in a cylindrical stainless steel plasma chamber of internal dimensions of $32 \mathrm{~cm}$ in diameter and $24 \mathrm{cminheight}$ (average volume of 19 L).A pumpingsystemcomprising of a primary pump and aturbo-molecular pump (Alcatel Adixen ATH 300) was used. Two gas inlets allow the injection of gas mixtures(Table 1) selected between argon, dinitrogen and dioxygen, and controlled by flow meters; a constant total flow rate of $10 \mathrm{sccm}$ was used for all the experiments, while respective flows were varied from 0 to 10 with a $2 \mathrm{sccm}$ step, and the $50 / 50 \%$ composition. The working pressure was 
measured by a capacitive gauge(Pfeiffer CCR364) and maintained between 0.2 and 1.5 Pa. The plasma was created through 12 microwave antennas, each of them ending with a dipole magnetthat ensures the electron cyclotron resonance (ECR) coupling at microwave $(2.45 \mathrm{GHz})$ frequency. The distance between two diametrically opposed magnets was fixed at $20 \mathrm{~cm}$. The applicatorswere uniformly distributed on the wall of the plasma chamber andindividually powered by a microwave generator (Sairem GMP20KED)viaadividerguide; dissipated powers in the range of 500 to $1500 \mathrm{~W}$ were studied, with a 250 W step.Eachapplicatorwasprovidedwithan impedance matcher meant to reduce the reflected power.Themicrowaveapplicators, theplasmachamber walls and the substrate holder were watercooled.The substrate holderallowed a free positioning of the substrate, for distances between the surfaces and the plasma glow of 0,6 and $12 \mathrm{~cm}$. Surfaces were treated during 5 or 10 minutes.

Table 1: Gaz mixtures used for low pressure ECR plasma. Total flow rates were fixed at 10 sccm. Flow rates reported for each mixture correspond to the underlined gas in the admxture.

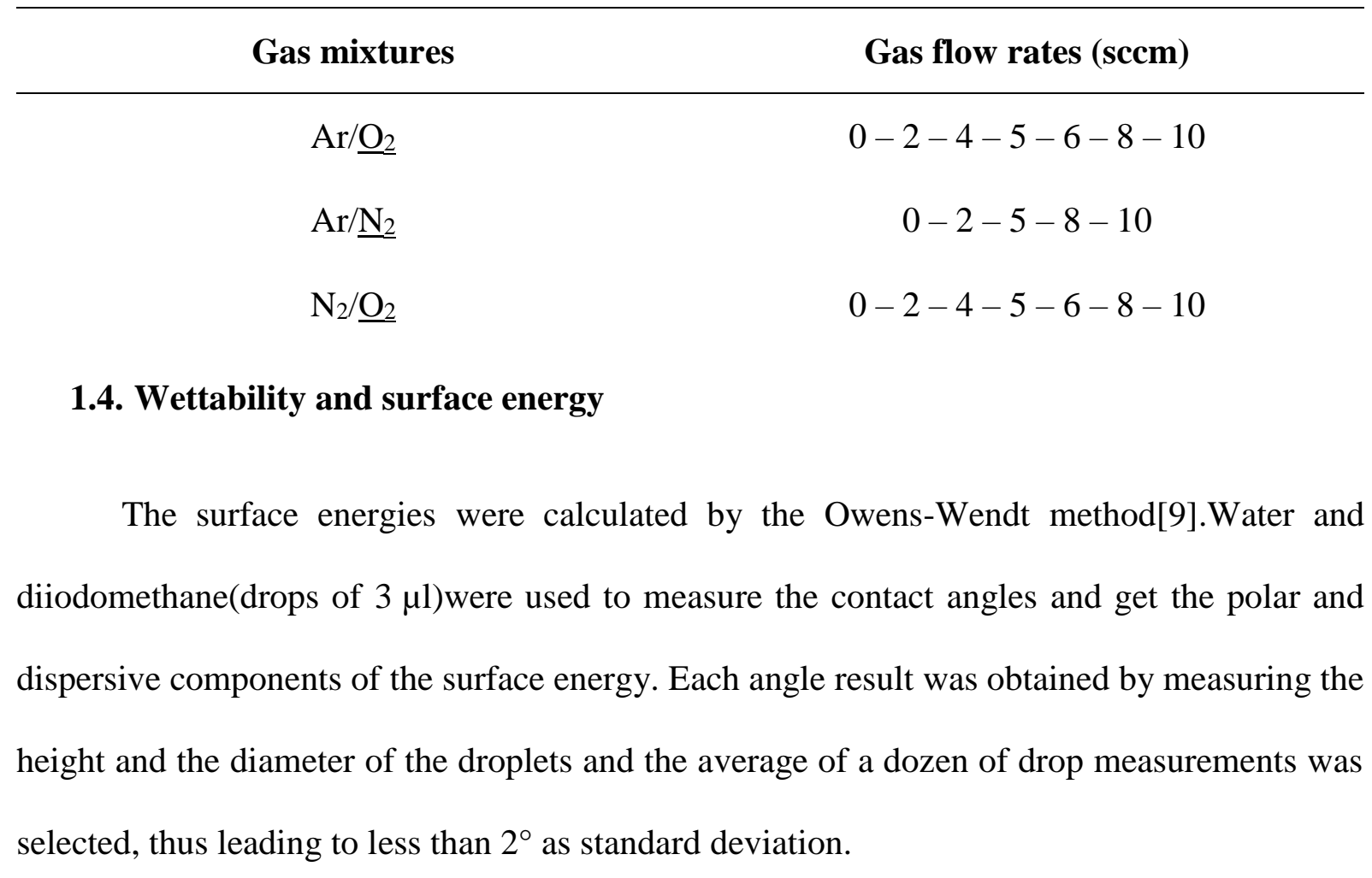


As the dispersive component of the surface free energy remained almost constant whatever the experimental conditions, compared to the variation of the polar component, we chose to consider the total surface free energyonly. Indeed, variations in the total surface energy are mainly dependant on the polar component in our case.

\subsection{Pull-off test}

The pull-off test method was used to characterize the adhesion of metallic thin films on polymer surfaces; in this study, $1 \mu \mathrm{m}$ aluminium thin films were grown on the polymer surfaces by thermal evaporation (Alcatel thermal evaporator chamber). The pull off test allows a reproducibleand relative study of adhesion stresses if one take several experimental precautions, as previously reported[8,10,11]. The measurements of practical adhesion stresses $\left(\sigma_{\text {adh }}\right)$ were performed with an Instron 4204 tensile strength system under a constant speed of $2 \mathrm{~mm} / \mathrm{min}$, by using $2 \mathrm{~cm}$-diameter aluminium dollies glued to the metallic thin films with an epoxy resin (Araldite 2011). In this study, statistical quantification of the adhesion stress was assured with the measurement of tensile strengths for four to six individual measurements.

\subsection{Chemical analysis}

The XPS analyses were performed with an X-rayPhotoelectron Spectrometer Axis Nova (Kratos Analytical). The X-ray source was a monochromatic $\mathrm{Al} \mathrm{K}_{\alpha}$ radiation. Pass energies of $80 \mathrm{eV}(1 \mathrm{eV}$ step $)$ and $20 \mathrm{eV}(0.1 \mathrm{eV}$ step) were employed for respectively the low and the highresolution spectra. The number of scans was 10 for each high-resolution spectrum of the XPS peaks (C 1s, O 1s and N 1s), while a sole scan was sufficient for each survey spectrum. The charge neutralizer was used for all the measurements because of the insulator properties of our polymer samples. The calibration was done with the main component of the $\mathrm{C} 1 \mathrm{~s}$ peak, which was assigned to a value of $284.7 \mathrm{eV}$ (aromaticcarbon).[12] The peak-fitting was performed 
using Casa XPS software using Gaussian/Lorentzian peak shapes. Full width at half maximum (FWHM) was calculated, as it can give more information on the variety in components attributed to each chemical shift.

\section{Results and Discussion}

The Figure 1shows the evolution of the practical adhesion stress $\left(\sigma_{\mathrm{adh}}\right)$ of aluminium thin films, as a function of the surface free energy. Each data point corresponds to the measurement of both surface free energy and practical adhesion stress for samples treated in the same plasma conditions. All the experimental conditions considered within the variation range as described in the experimental section are reported here. This figure summarizes all of the corresponding results for (i) all scan speeds, the three numbers of scans and the three plasma-surface distancesconsidered for the atmospheric pressure plasma, and (ii) all the powers, the treatment times, the plasma-surface distances, and different gas-phase compositions for the low pressure plasma. First,a correlation of the surface wettability and adhesion potential towards metallic coatings is observedin the case of the atmospheric pressure plasma treatment: the surface free energy increases from $41.5 \pm 0.4 \mathrm{~mJ} / \mathrm{m}^{2}$ to $78.9 \pm 0.8 \mathrm{~mJ} / \mathrm{m}^{2}$ while the associated practical adhesion stress evolves from $1.2 \pm 0.2 \mathrm{MPa}$ to $4.0 \pm 0.5 \mathrm{MPa}$. For surface free energies values higher than $60 \mathrm{~mJ} / \mathrm{m}^{2}$, the practical adhesion stress seems to be linearly proportional to the surface free energy:the higher the surface free energy, the higher is the practical adhesion stress. In the case of the low pressure plasma treatment, the lowest surface energy value is $77 \pm 2 \mathrm{~mJ} / \mathrm{m}^{2}\left(\sigma_{\mathrm{adh}}=3.1 \pm 0.2 \mathrm{MPa}\right)$, increasing up to a saturation of the surface free energy at $81.4 \pm 0.2 \mathrm{~mJ} / \mathrm{m}^{2}\left(\sigma_{\mathrm{adh}}=4.8 \pm 0.4 \mathrm{MPa}\right)$. While both surface free energies and practical adhesion stress values are higher in the case of the low pressure plasma treatment, this study shows that the low pressure plasma results are in the continuity of the atmospheric 
pressure plasma ones. We still observe proportionality between the adhesion stresses and the surface free energies. This implies a similar dependence of these surface characteristics on the mechanisms of the functionalizationofboth plasmas. Such an increase in both surface energy and practical adhesion of metallic coatings has already been observed, especially when a significant increase in the polar contribution of the surface energy is induced by plasma functionalization.[13,14]A similar behaviour is observed for both plasmas, yet the low pressure plasma allows a chemical functionalization that induces higher both surface free energies and practical adhesion stresses.

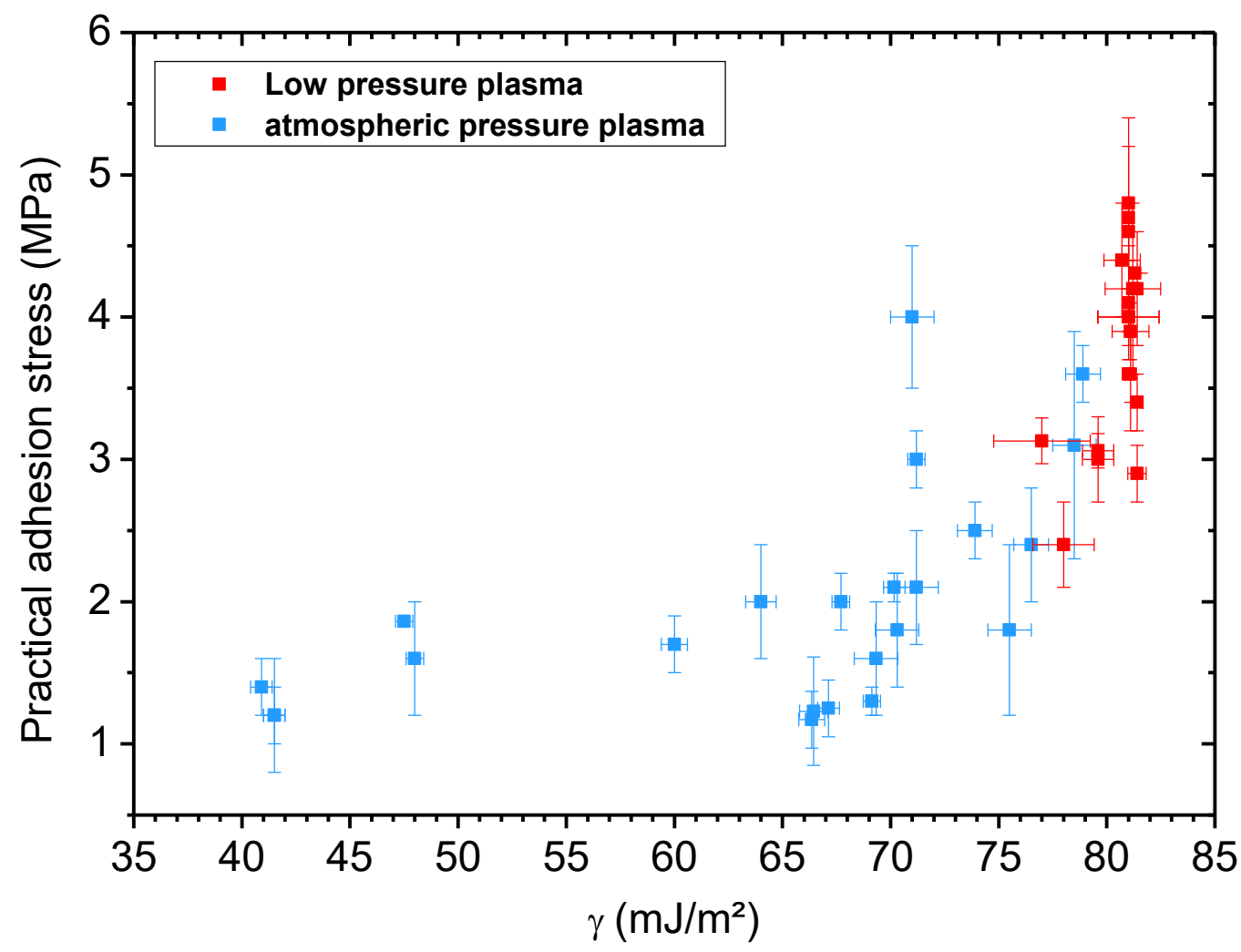

Figure 1 dependence of the practical adhesion stress on the surface free energy, for the atmospheric pressure and low pressure plasmas.

A detailed study of the rupture mechanisms has been made in the case of the atmospheric pressure plasma in a previous work.[8] In summary, the rupture mode was evolvingfrom adhesivefor practical adhesion stress values of $1.2<\sigma_{\mathrm{adh}}<2.0 \mathrm{MPa}$ to cohesive in the metallic 
layerfor $2.0<\sigma_{\mathrm{adh}}<3.5 \mathrm{MPa}$, and finally tothe peeling of the polymer surface for $\sigma_{\mathrm{adh}}>3.5 \mathrm{MPa}$. This evolution of the rupture mode was not observed in the case of the low pressure plasma for which it was always adhesive, even for practical adhesion stress values higher than that obtained for the atmospheric pressure plasma.

This evolution in the rupture process for the atmospheric pressure plasma is attributed to a thermal shock when the surface is exposed to the plasma, inducing a thermal degradation of the mechanical properties of the polymer.[15-17] This thermal shock does not occur for the low pressure plasma treatments, thanks to a lower temperature of the gas and the cooling of the substrate. As the mechanical properties of the substrate are more preserved, the assembly is able to sustain more stress, asthe mechanical properties of the interfacial materials influences the assembly strength.[18]To verify this hypothesis, an experiment was conducted where the thermal shock was reduced in the case of the atmospheric pressure plasma. Samples were heated in an oven for one hour at $90{ }^{\circ} \mathrm{C}$, before being treated by the atmospheric pressure plasma in the same conditions for which the PEEK rupture was observed. While the practical adhesion stress remained on the same level as what was obtained without the thermal pre-conditioning (around 3.6 MPa), all ruptures were adhesive. This shows that heating the substrate before plasma treatment, to the same temperature as measured during plasma exposition, prevents the materials rupture during pull-off. The weakening of the substrate is thus dependent on the heating rate during treatment, and less on the absolute temperature.

To check the effect of the chemistry on the surface free energy and thus the adhesion potential, XPS measurements were conducted in the same plasma conditionsstudied in the previous experiment.Typical low resolution spectra are shown inFigure 2, while high resolution XPS spectra are shown in Figure 3 andFigure 4. 

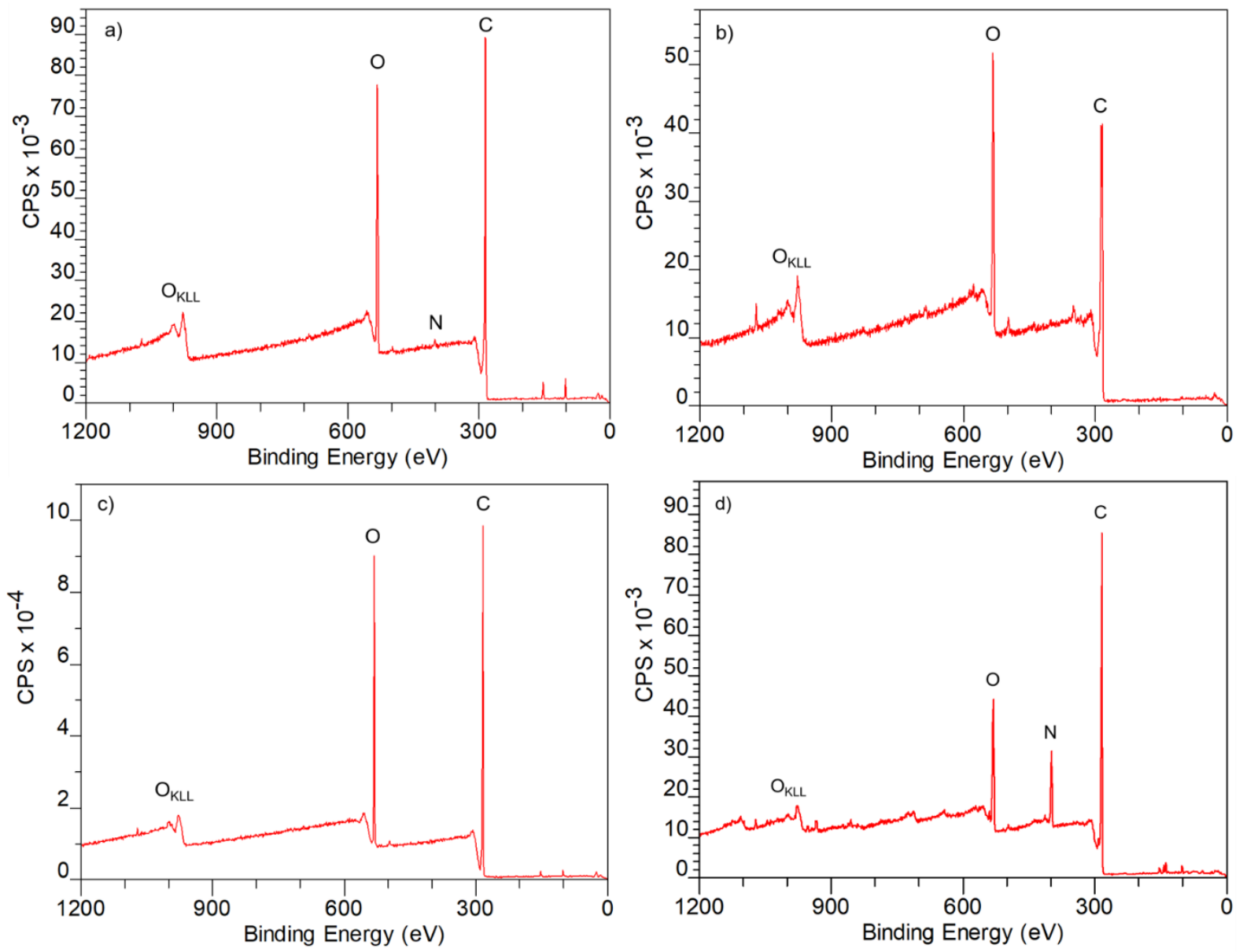

Figure 2 : Low resolution spectra for a) pristine PEEK; $b$ ) atmospheric pressure plasmatreated PEEK $(v=10 \mathrm{~mm} / \mathrm{s}, h=2 \mathrm{~cm}, 2$ scans $)$; low pressure plasma-treated PEEK: $P=1500 \mathrm{~W}, t=$ 10 min, $p=0.3 \mathrm{~Pa}$ considering gas admixtures of c) $50-50 \% \mathrm{Ar}-\mathrm{O}_{2}$; d) $50-50 \% \mathrm{~N}_{2}-\mathrm{O}_{2}$

Erreur ! Source du renvoi introuvable.shows the XPS low resolution spectra for the range from 0 to $1200 \mathrm{eV}$ for pristine PEEK and plasma-treated PEEK. In the case of pristine PEEK, we can consider 3 major peaks at $284,7 \mathrm{eV}, 400 \mathrm{eV}$ and $532 \mathrm{eV}$ for respectively the main $\mathrm{C} 1 \mathrm{~s}, \mathrm{O} 1 \mathrm{~s}$ and $\mathrm{N}$ 1s peaks. The Auger $\mathrm{O}_{\mathrm{KLL}}$ peak can also be observed at $986 \mathrm{eV}$. This spectrum shows that traces of nitrogen can be detected near the surface. When the polymer is plasma-functionalized, variations in the relative intensities can be observed, especially for the $\mathrm{O} 1 \mathrm{~s}$ and $\mathrm{C}$ 1s peaks, specifically shown in the case of the atmospheric plasma treatment. It should be noted that for oxidizing plasmas, i.e. atmospheric pressure and low pressure plasma containing $\mathrm{Ar}$ and/or $\mathrm{O}_{2}$, surface traces of nitrogen disappear, as shown by the absence of the main $\mathrm{N}$ 1s peak for the corresponding plasma conditions. Nitrogenation of the surface is 
however efficient in the case of $\mathrm{N}_{2}$-containing low pressure plasma, as the $\mathrm{N} 1 \mathrm{~s}$ main peak intensity significantly increases, implying a more complex functionalisation by the addition of nitrogen species onto the surface. 

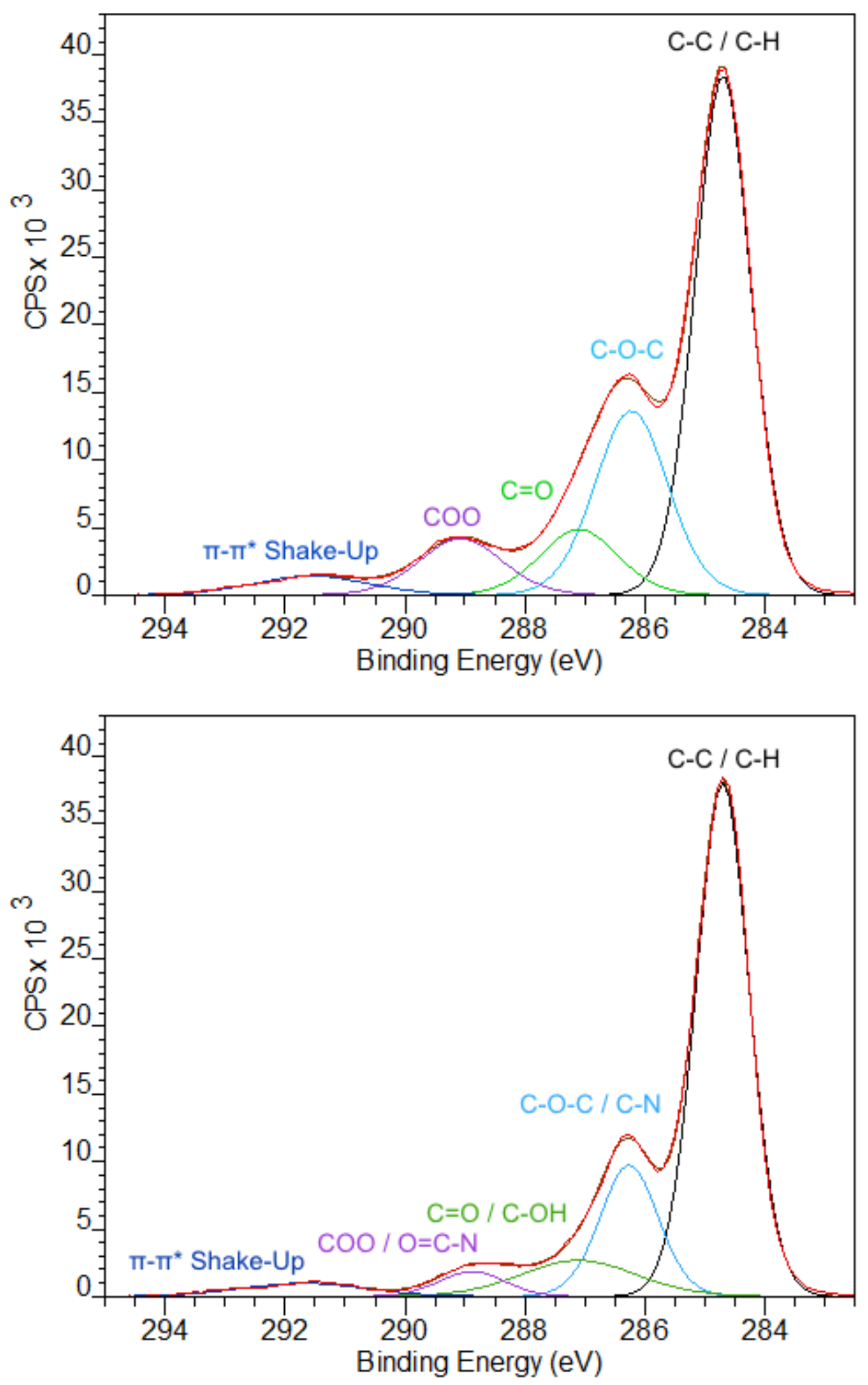

Figure 3 : C 1s peak for high and low pressure plasma modified surface of PEEK; plasma conditions are:atmospheric pressure plasma (top): $v=10 \mathrm{~mm} / \mathrm{s}, h=2 \mathrm{~cm}, 2$ scans; low pressure plasma (bottom): $\mathrm{P}=1500 \mathrm{~W}, 50-50 \% \mathrm{~N}_{2}-\mathrm{O}_{2}, t=10 \mathrm{~min}, \mathrm{p}=0.3 \mathrm{~Pa}$. 
Table 2 :data of the $C 1$ s peak components fitting of atmospheric and low pressure plasma treated PEEK surfaces.

\begin{tabular}{ccccccc}
\hline & \multicolumn{2}{c}{ Pristine PEEK } & \multicolumn{2}{c}{ Atm. pressure plasma } & \multicolumn{2}{c}{ Low pressure plasma } \\
\hline $\begin{array}{c}\text { BE } \\
\text { position } \\
(\mathbf{e V})\end{array}$ & $\begin{array}{c}\text { FWHM } \\
(\mathrm{eV})\end{array}$ & $\begin{array}{c}\text { Peak Area } \\
(\%)\end{array}$ & $\begin{array}{c}\text { FWHM } \\
(\mathrm{eV})\end{array}$ & $\begin{array}{c}\text { Peak Area } \\
(\%)\end{array}$ & $\begin{array}{c}\text { FWHM } \\
(\mathrm{eV})\end{array}$ & $\begin{array}{c}\text { Peak Area } \\
(\%)\end{array}$ \\
$\mathbf{2 8 4 . 7}$ & 1.0 & 73.2 & 1.1 & 53.6 & 1.0 & 64.2 \\
$\mathbf{2 8 6 . 3}$ & 1.2 & 22.2 & 1.4 & 24.0 & 1.1 & 18.0 \\
$\mathbf{2 8 7 . 1}$ & 1.2 & 1.8 & 1.4 & 9.4 & 2.4 & 10.3 \\
$\mathbf{2 8 8 . 9}$ & 1.5 & 0.8 & 1.7 & 9.0 & 1.3 & 3.7 \\
$\mathbf{2 9 1 . 7}$ & 2.2 & 2.0 & 2.2 & 4.0 & 2.4 & 3.8
\end{tabular}

Figure 3(top)shows the XPS C1s peak for the atmospheric-pressure-plasmatreated surface of PEEK. Peak fitting results are shown in the Table 2. The $\mathrm{C}$ 1s peak is composed of four main components: the aromatic carbon component (marked as $\underline{\mathrm{C}}-\mathrm{C} / \underline{\mathrm{C}}-\mathrm{H}$, at $284.7 \mathrm{eV}$ ), the $\underline{\mathrm{C}}-\mathrm{O}-\underline{\mathrm{C}}$ (ether) at $286.3 \mathrm{eV}$, the $\underline{\mathrm{C}}=\mathrm{O}$ (ketone) and $\underline{\mathrm{COH}}$ at $287.1 \mathrm{eV}$ and the $\underline{\mathrm{COO}}$ component (ester, acid and groups) at $288.9 \mathrm{eV}$. A low-intensity, broad peak appearing at $291.7 \mathrm{eV}$ is attributed to the $\pi-\pi^{*}$ shake-up of the aromatic rings. The XPS C1s peak of the low pressure $\mathrm{N}_{2} / \mathrm{O}_{2}$ plasma-treated samples (Figure 3bottom) shows a similar shape as that obtained for the atmospheric pressuretreatment. The corresponding fitted values, as well as the values obtained for pristine PEEK, are also reported in Table 2. It should be noted that the measured proportions of functional groups in the case of pristine PEEK are different from the expectedproportions. Indeed, pristine PEEK should be composed of $73.7 \%$ of aromatic carbons, $21.0 \%$ of $\underline{\mathrm{C}}-\mathrm{O}$ and $5.3 \%$ of $\underline{\mathrm{C}}=\mathrm{O}$, while no $\underline{\mathrm{COO}}$ should be observed. Yet, different proportions of the functional groups are measured as well as traces of $\mathrm{COO}$ functions; the relative proportions are thus recalculated as 74.7, 22.4, 1.9 and $1.0 \%$ for respectively aromatic carbons, $\mathrm{C}-\mathrm{O}-\mathrm{C}, \mathrm{C}=\mathrm{O}$ and COO functional groups. This difference could indicate a slight oxidation of the surface as well as traces of additives. For this work, COO surface concentration of pristine PEEK was not considered. Furthermore, attribution of $\underline{\mathrm{C}}-\mathrm{OH}$ to the $287.1 \mathrm{eV}$ peak (which usually appears at 
$286.5 \mathrm{eV}[12])$ can be explained as follows : (i) as all functional groups in PEEK molecule are in the vicinity of at least one aromatic ring, electron depletion is to be expected. Shielding effect is lower and functional groups appear at higher binding energies ; (ii) the high FWHM of the corresponding peak does not allow the attribution of a precise binding energy to the $\mathrm{C}-\mathrm{OH}$ component, and thus is mixed with the $\mathrm{C}=\mathrm{O}$ component.

Whatever the plasma treatment, the main C 1s spectrum is composed of the same four main components.As nitrogen presence has been observed thanks to the low resolution spectra, nitrogen species are to be considered and may contribute to the existing components: $\underline{\mathrm{C}}-\mathrm{N}$ component at $286.3 \mathrm{eV}$ and $\mathrm{O}=\underline{\mathrm{C}}-\mathrm{N}$ component (amide) at $288.9 \mathrm{eV}$. The $\underline{\mathrm{C}}-\mathrm{N}$ part of the $286.3 \mathrm{eV}$ component could not discriminate the different carbon-nitrogen bonds as their respective shifts are very close to each other: $\underline{\mathrm{C}}-\mathrm{N}(285.5-286.3 \mathrm{eV}), \underline{\mathrm{C}}=\mathrm{N}(285.5-286.6 \mathrm{eV})$ or $\underline{\mathrm{C}} \equiv \mathrm{N}(286.7-287.0 \mathrm{eV}) \cdot[12,19]$ Hydroxylformation, mainly as phenol groups, is assigned together with the ketone component at $287.1 \mathrm{eV}$. This can be explained by the slightly higher binding energy for aromatic alcohols in respect to aliphatic alcohols, and that the fit leads to an increase in the full width at half maximum(FWHM), from 1.2 for untreated PEEK, to values around $2.4 \mathrm{eV}$ after low-pressure-plasma treatment. In the case of the atmospheric pressure plasma-treated surfaces, the measured $287.1 \mathrm{eV}$ component is characterized by a FWHM calculated around $1.5 \mathrm{eV}$ which could indicate a lower probability to form phenols on the PEEK surface, whatever the considered experimental conditions.Further analysis of the $\mathrm{C} 1 \mathrm{~s}$ (and O 1s) spectra showed that few plasma-treatment conditions allowed a significant surface concentration of phenols. 

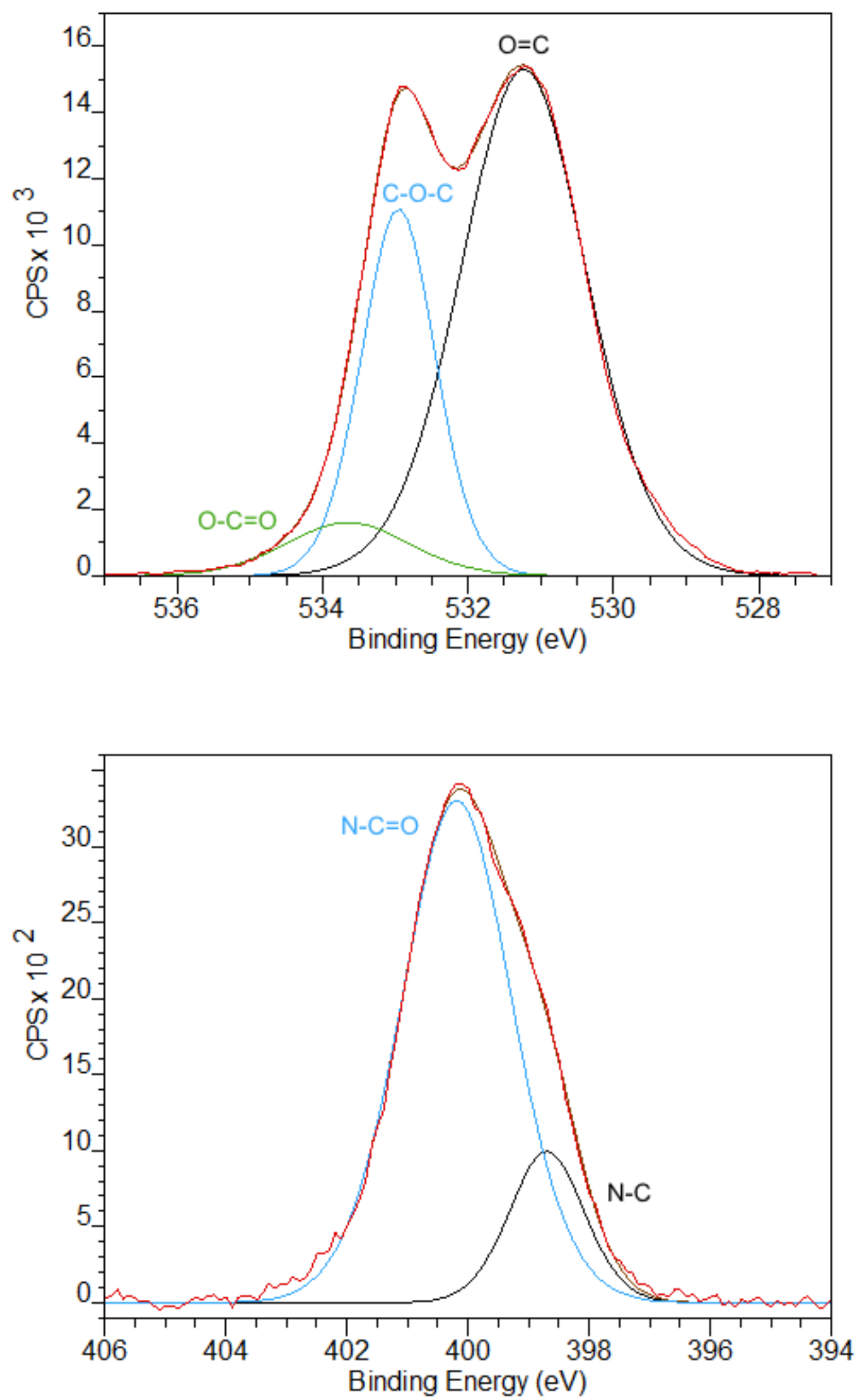

Figure 4: $\mathrm{O} 1 \mathrm{~s}$ and $\mathrm{N} 1 \mathrm{~s}$ peak for low pressure $\left(\mathrm{N}_{2} / \mathrm{O}_{2}\right)$ plasma modified surface of PEEK; plasma conditions are: $\mathrm{P}=1500 \mathrm{~W}, 50-50 \% \mathrm{~N}_{2}-\mathrm{O}_{2}, t=10 \mathrm{~min}, \mathrm{p}=0.3 \mathrm{~Pa}$. 
Table 3 data of the $\mathrm{O} 1 \mathrm{~s}$ and $\mathrm{N} 1 \mathrm{~s}$ peak components fitting of $\mathrm{N}_{2} / \mathrm{O}_{2}$ low pressure plasma treated PEEK surfaces.

\begin{tabular}{cccccc}
\hline \multicolumn{3}{c}{ O 1s peak } & \multicolumn{3}{c}{ N 1s peak } \\
\hline $\begin{array}{c}\text { BE position } \\
(\mathbf{e V})\end{array}$ & FWHM & Peak Area & BE shift & FWHM & Peak Area \\
$\mathbf{5 3 1 . 3}$ & $(\mathrm{eV})$ & $(\%)$ & $(\mathbf{e V})$ & $(\mathrm{eV})$ & $(\%)$ \\
$\mathbf{5 3 3 . 3}$ & 2.0 & 65.2 & $\mathbf{3 9 8 . 7}$ & 1.5 & 17.75 \\
$\mathbf{5 3 4 . 0}$ & 1.2 & 27.9 & $\mathbf{4 0 0 . 2}$ & 2.1 & 82.25 \\
& 2.0 & 6.9 & & &
\end{tabular}

Numerical results of both spectra are reported in Table 3. Figure 4(top) showsthat the $\mathrm{O} 1 \mathrm{~s}$ peak is composed of three main components, appearing at $531.6,533.3$ and $534.0 \mathrm{eV}$, which are respectively attributed to $\underline{\mathrm{O}}=\mathrm{C}$ (ketones) or $\underline{\mathrm{O}}=\mathrm{CR}-\mathrm{NR}$ 'R' (amides), C-$\underline{\mathrm{O}}-\mathrm{C}$ (ether) and $\underline{\mathrm{O}}-\mathrm{C}=\mathrm{O}$ (ester/acidic)bonds. The relatively broad peaks of the $\underline{\mathrm{O}}=\mathrm{C}$ and $\underline{\mathrm{O}}-\mathrm{C}=\mathrm{O}$ components with FWHM values nearing $2 \mathrm{eV}$, show a more complex contribution that could not be precisely fitted, due to the narrow variations in the shifts of the different bonds. Thus, amide and other oxidized bonds could contribute to either of the component peaks. However, the calculated areas of the respective peaks are consistent with what could be obtained from the $\mathrm{C} 1 \mathrm{~s}$ spectra: The $\mathrm{O} / \mathrm{C}$ ratio as calculated from the $\mathrm{C} 1 \mathrm{~s}$ high resolution peak is almost equal to the $\mathrm{O} / \mathrm{C}$ ratio as calculated from the $\mathrm{O}$ 1s peak.It should be noted that in the particular example shown in Figure 4 and Table 3, a strong contribution of the amide groups can be observed for the 531.3 eVcomponent in the case of the $\mathrm{O} 1 \mathrm{~s}$ spectrum. However,for oxidative plasma conditions (while using argon and/or oxygen), the $531.3 \mathrm{eV}$ component is significantly lower than the $533.3 \mathrm{eV}$ (ether group) component. While the contribution of nitrogenated bonds can induce significant variations in the $\mathrm{O} 1 \mathrm{~s}$ components relative to exclusive oxidative plasma conditions, their contributions are still limited due to slightly lower proportions in atomic nitrogen as measured with low resolution spectra. Indeed, for the example shown in Figure 4, for which the highest 
nitrogen concentration was calculated, elemental composition of the sample was measured at 16,9 and $75 \%$, for respectively $\mathrm{O}, \mathrm{N}$ and $\mathrm{C}$.

The N 1s (Figure 4 bottom)peak is composed of two main components: theN-C (at $398.7 \mathrm{eV}$ and the $\underline{\mathrm{N}}-\mathrm{C}=\mathrm{O}$ (at $400.2 \mathrm{eV}$ ). It should be noted however that it is very delicate to assign more peaks in the fitting process as the $\mathrm{N} 1 \mathrm{~s}$ spectrum often consists of a broad peak including all the nitrogen species, for which the binding energy shifts are close from each other.As for an example, N-C (amines, imines, nitriles and amides) are observed in the $399-$ $400.3 \mathrm{eV}$ range.[12,20]In fact, the amide component $(400.2 \mathrm{eV})$ should more likely be composed of several attributions, which could be explained by the relatively large FWHM $(2.13 \mathrm{eV})$, while the main $\mathrm{N} 1 \mathrm{~s}$ peak is roughly $3 \mathrm{eV}$ broad. However, the shift of this component can be mainly attributed to the amide group, as its relative intensity is linearlyproportional to the dioxygenpercentage in the $\mathrm{N}_{2} / \mathrm{O}_{2}$ gas phase. Its relative high intensity, even for pure $\mathrm{N}_{2}$ plasmas, shows that the surface nitrogen is preferentially added as amide groups. The absence of peaks at higher binding energies $(406-408 \mathrm{eV})$ excludes the formation of functional groups where $\mathrm{N}$ atoms are bonded to $\mathrm{O}$ atoms (nitro, oxime, and nitrate groups).Nevertheless, the $\mathrm{N}$ 1s peak fitting indicates a low proportion of $\underline{\mathrm{N}}-\mathrm{C}$ added on the surface, in respect to the amide groups, which indicates a lower probability to form pure C-N bonds instead of $\mathrm{O}=\mathrm{C}-\mathrm{N}$; the formation of multiple-bond carbon-nitrogen functional groups is thus even less probable[21,22].

Based on the conclusions from the $\mathrm{N}$ 1s study, we can make the assumption that for the C 1s spectra the $\underline{\mathrm{C}}-\mathrm{N}$ part of the $286.3 \mathrm{eV}(\underline{\mathrm{C}}-\mathrm{O}-\underline{\mathrm{C}} / \underline{\mathrm{C}}-\mathrm{N})$ components is mainly attributed to amine groups. The functionalization of the surface by a nitrogen/oxygen plasma, in terms of relative abundance of nitrogen groups, follows the probability sequence $\mathrm{N}-\mathrm{C}=\mathrm{O}>\mathrm{C}-\mathrm{N}>>$ $\mathrm{C}=\mathrm{N} / \mathrm{C} \equiv \mathrm{N}$.Thanks to better resolution of the different components, the $\mathrm{C} 1 \mathrm{~s}$ peak is chosen to 
further describe the correlation of the surfaces properties with the surface chemistry, while the $\mathrm{O} 1 \mathrm{~s}$ and $\mathrm{N} 1 \mathrm{~s}$ peaks are used to check the attribution of peaks and the consistency of the concentration ratios.

It should be noted that the low resolution spectra corresponding to low pressure plasma treatments with $\mathrm{Ar} / \mathrm{O}_{2}$ mixtures did not show any trace of atomic nitrogen added on the surface, contrary to what was observed in the case of $\mathrm{N}_{2}$-containing mixtures. The presence of atomic nitrogen on the surface was also not observed for atmospheric pressure plasma treatment. We can thus assume that (i) the $286.3 \mathrm{eV}$ component does not contain any proportion of C-N species $(\underline{\mathrm{C}}-\mathrm{N}, \underline{\mathrm{C}}=\mathrm{N}$ and $\underline{\mathrm{C}} \equiv \mathrm{N}$ ), and (ii) the $288.9 \mathrm{eV}$ component does not contain the contribution of amide groups. The absence of nitrogen in both atmospheric pressure plasma and $\mathrm{Ar} / \mathrm{O}_{2}$ low pressure plasma (in the later, thanks to the high purity of the gas) implies a chemical functionalization of the surface by the exclusive formation of oxygenated species; components appearing at 286.3 and $288.9 \mathrm{eV}$ are solely respectively attributed to ether ( $\underline{\mathrm{C}}-\mathrm{O}-\underline{\mathrm{C}})$ and ester/acidic ( $\underline{\mathrm{COO}}$ and $\underline{\mathrm{COOH}})$ groups. 


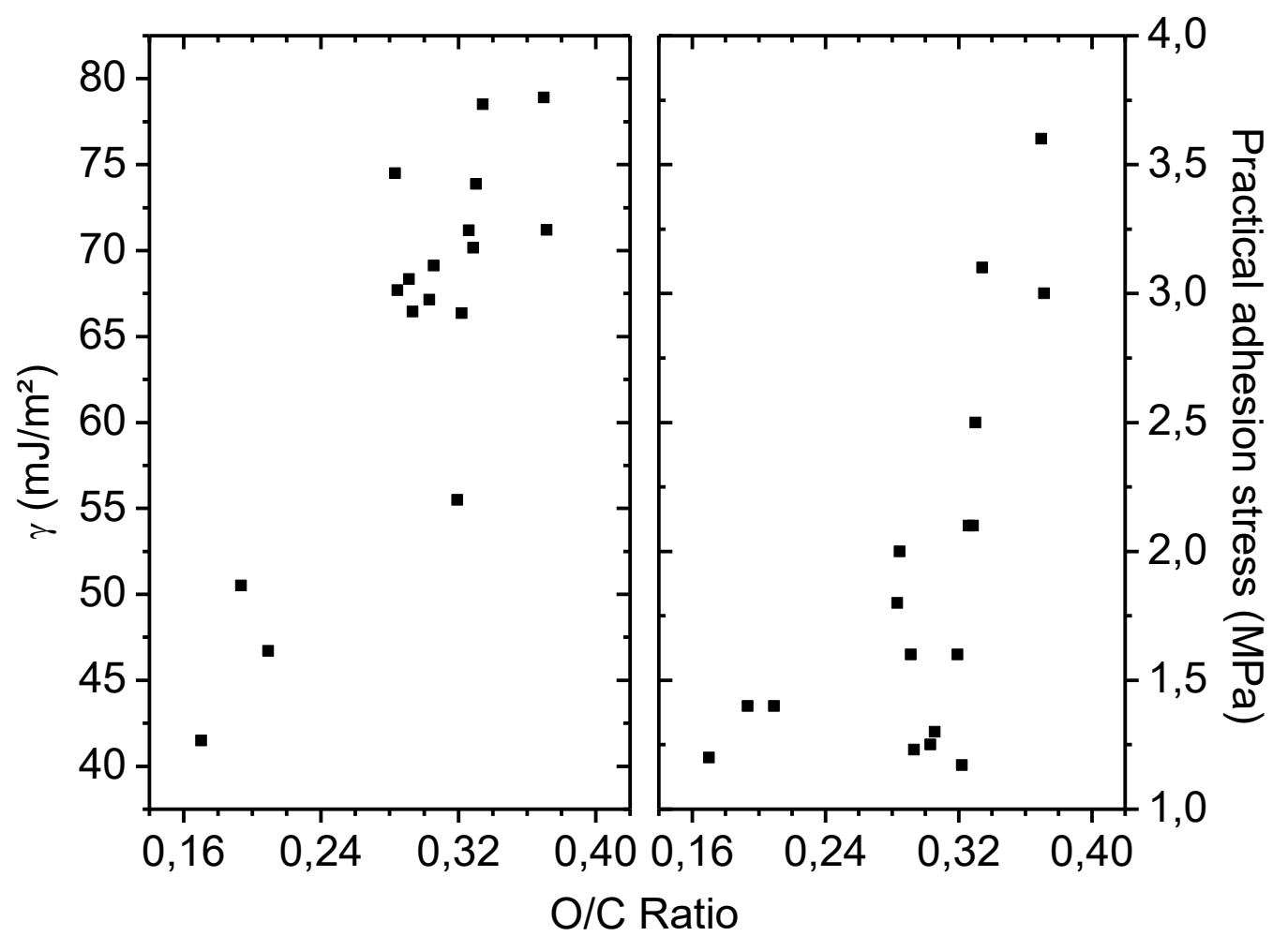

Figure 5dependence of the surface free energy (left) and practical adhesion stress (right) on the O/C ratio for the atmospheric pressure plasma.

To further understand the correlationreported in the Figure 1between the surface free energy and the practical adhesion,the quantification of the surface chemistry is now addressed for each of all the experimental parameters considered in the case of atmospheric pressure plasma treatment.The Figure 5showsthat the surface free energy and the practical adhesion stress increase from 41.5 to $78.9 \mathrm{~mJ} / \mathrm{m}^{2}$ and from 1.2 to $3.6 \mathrm{MPa}$, respectively, while the $\mathrm{O} / \mathrm{C}$ ratio, calculated from the XPS elemental compositions increases from 0.17 (untreated) to 0.37. A certain proportionality between the surface free energy - hence, the practical adhesion stress - and the $\mathrm{O} / \mathrm{C}$ ratio is observed. This proportionality between the surface properties (wettability and chemistry) and the practical adhesion implies a strong correlation between the oxidization degree of the surface,the surface free energy and the adhesion potential. 
To define which chemical group on the surface has more weight in the contribution to the efficiency of the enhancement of the adhesion potential, the same study was carried outconsideringeach components of the main carbon peak: the analysis of the correlations was conducted based on the high resolution spectra of the $\mathrm{C}$ 1s peak, which component ratios are plotted in respect to the surface free energies and the practical adhesion stress values.

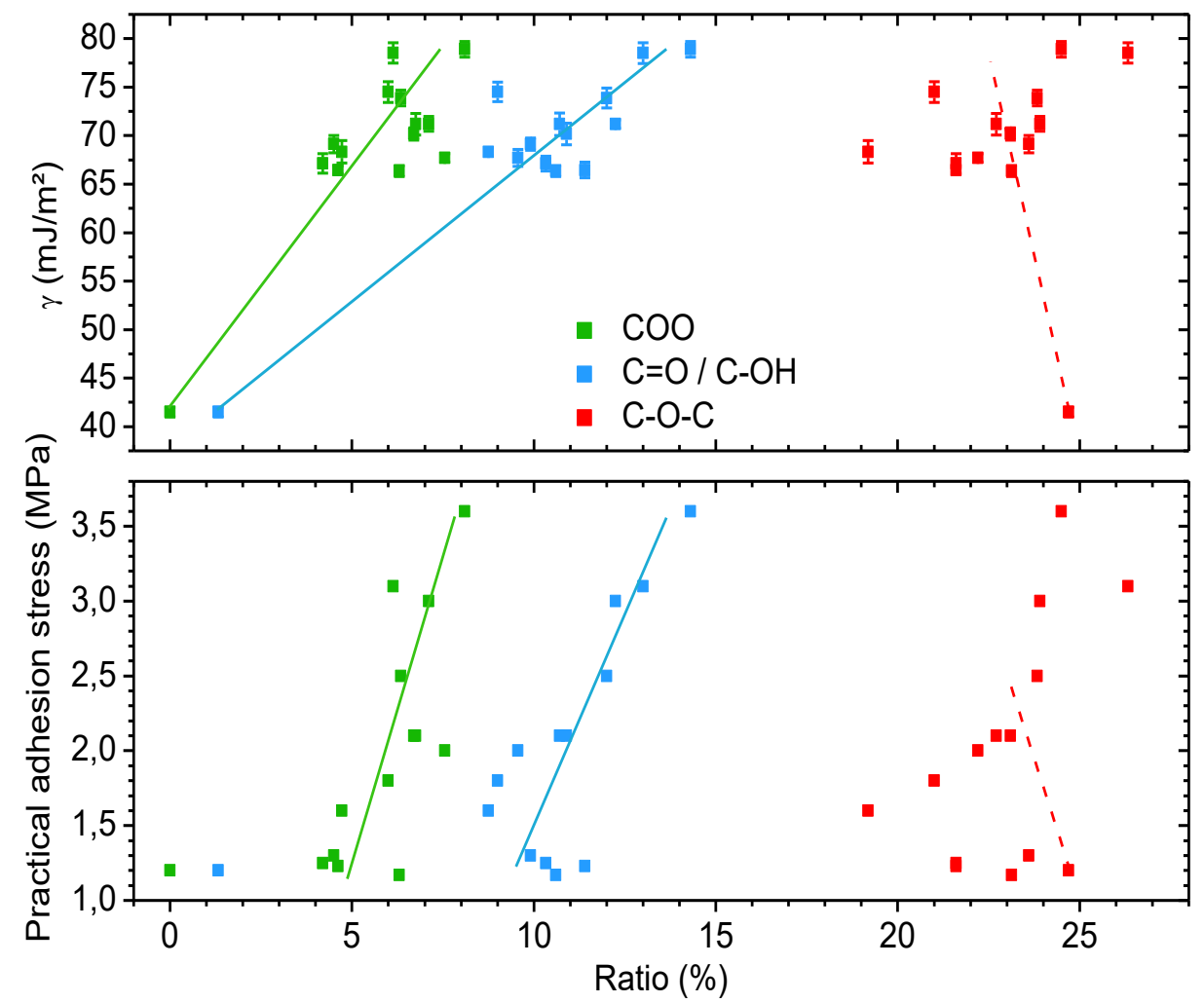

Figure 6 dependence of the surface free energy (top) and practical adhesion stress (bottom) on the ratio of the $C 1$ s componentsfor the atmospheric pressure plasma.

In the case of atmospheric pressure plasma treatments, the Figure 6shows that on the one hand, the surface free energy increases from $41.5 \mathrm{~mJ} / \mathrm{m}^{2}$ (untreated surface)to $78.9 \mathrm{~mJ} / \mathrm{m}^{2}$ when the $\mathrm{COO}$ and $\mathrm{C}=\mathrm{O}$ ratios increase respectively from 0 to $8.1 \%$ and from 1.9 to $14.3 \%$. This increase in the surface free energy is however not supported by a significant increase in the CO-C component: the measured ratio for the untreated surface is $22.6 \%$, but after treatment, it varies from values as low as 19.2 , up to $26.3 \%$. The apparent initial decrease of $5.5 \%$ for the 
C-O-C component, from the untreated to treated surfaces is due to the quick increase in the respective relative proportions of both $\mathrm{C}=\mathrm{O}$ and $\mathrm{COO}$ components after treatment. This means that the surface free energy is mainly proportional to the surface concentration of the most polar groups, i.e. $\mathrm{C}=\mathrm{O}$ and $\mathrm{COO}$ functional groups. On the other hand, asimilar observation can be made for the evolution of the practical adhesion stress: it increases from 1.2 to $3.6 \mathrm{MPa}$ with the increasing proportions in $\mathrm{C}=\mathrm{O}$ and $\mathrm{COO}$, showing a relationship between surface concentration of polar groups and practical adhesion. Variations in the $\mathrm{C}-\mathrm{O}-\mathrm{C}$ proportions seem to have almost no effect on the practical adhesion stress. The more diffuse evolution of both the surface free energy and the adhesion potential as a function of the C-O-C component ratios indicates no obvious relationship between the concentration of ether groups and the surface free energy or practical adhesion stress. However, it is difficult to discriminate which, from the $\mathrm{C}=\mathrm{O}$ and COO proportions, has more effect on the surface energy and on the adhesion potential. Indeed, both proportions in these polar groups increase at the same time and seem to act the same way on the surface free energy and on the practical adhesion. Nevertheless, this study shows that the evolution of the surface properties is strongly correlated to the proportion in the polar groups, as shown by the linear proportionality between them.

As we observed a similar behaviour in the proportionality between the practical adhesion stress and the surface free energy for both of the plasmas studied, a similar study of the effect of the surface chemistry on the surface properties is done with low pressure plasma treated surfaces. 


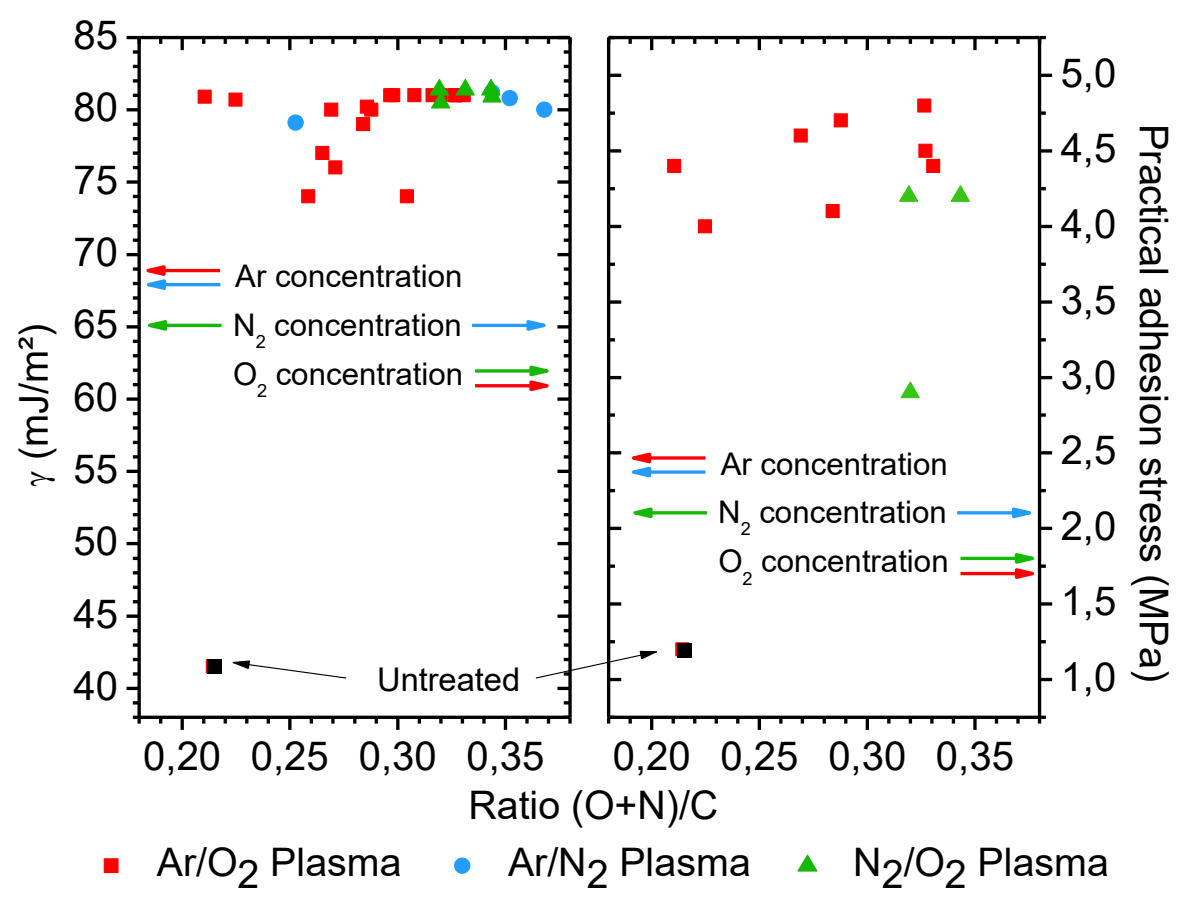

Figure 7 dependence of the surface free energy (left) and practical adhesion stress (right) on the $(O+N) / C$ ratiofor the low pressure plasma. The arrows directionsrepresent the increase in the respective gases concentrations, while their colours refer to the respective mixtures considered.

The Figure 7 shows the evolution of the surface free energy and the practical adhesion stress as a function of the $(\mathrm{O}+\mathrm{N}) / \mathrm{C}$ ratio, which is proportional to the ratio of the reactive gas injected in the plasma chamber. As nitrogen and oxygen species added on the surface can contribute to the increase in the surface free energy and in the practical adhesion stress, taking into accountboth atomic $\mathrm{O}$ and $\mathrm{N}$ to $\mathrm{C}$ ratio is needed to check the properties correlation. It is however important to point out that,as mentioned before, no nitrogen was detected on the surfaces for plasma treatments withAr/ $\mathrm{O}_{2}$ mixtures, but was confirmed for $\mathrm{Ar} / \mathrm{N}_{2}$ mixtures.In that case, the concentration of atomic $\mathrm{N}$ is almost equal to 0 , and thus the $(\mathrm{O}+\mathrm{N}) / \mathrm{C}$ ratio is equivalent to the $\mathrm{O} / \mathrm{C}$ ratio; $\mathrm{O} / \mathrm{C}$ was the ratio that was considered in the case of the atmospheric pressure plasma treatment. This plot shows that most of the surface free energy values saturate at $81 \mathrm{~mJ} / \mathrm{m}^{2}$; yet several treated surfaces showed surface free energy values significantly lower down to $75 \mathrm{~mJ} / \mathrm{m}^{2}$.The practical adhesion stress increases from $1.2 \pm 0.4 \mathrm{MPa}$ in the untreated case to $4.1 \pm 0.1 \mathrm{MPa}$, and up to $4.8 \pm 0.2 \mathrm{MPa}$, when the $(\mathrm{O}+\mathrm{N}) / \mathrm{C}$ ratio increases from 0.21 to 
0.33, in the case of an $\mathrm{Ar} / \mathrm{O}_{2}$ plasma, and (ii) from $2.9 \pm 0.4 \mathrm{MPa}$ to $4.1 \pm 0.1 \mathrm{MPa}$ when the ratio increases from 0.32 to 0.33 in the case of the $\mathrm{N}_{2} / \mathrm{O}_{2}$ plasma. The lowest adhesion stress value measured $(2.9 \pm 0.2 \mathrm{MPa})$ corresponds to a pure $\mathrm{N}_{2}$ plasma, while it increases when more oxygen is injected (up to $4.5 \mathrm{MPa}$ ). On the one hand, this shows that the surface free energy seems to be independent on the $(\mathrm{O}+\mathrm{N}) / \mathrm{C}$ ratio due to its quick saturation, showing the high efficiency of this plasma chemistry to functionalize the surface. The small variation of the surface free energy makes it more difficult to clearly define the role of the surface chemistry on the surface free energy evolutions; what is more, Arplasma treatments are known to oxidize the surface by post-treatment reactions[14]. On the other hand, the increase in the practical adhesion stress as a function of the $(\mathrm{O}+\mathrm{N}) / \mathrm{C}$ shows a significant proportionality between the adhesion and the surface composition. The low adhesion observed for high dinitrogen concentrations in the low pressure treatment implies a decrease in the practical adhesion stress when a majority of nitrogen species (amines and amides) in regards of the oxidized groups is added on the surface. Nevertheless, the practical adhesion stress is proportional to the oxidization/nitrogenation degree, as it was observed for the atmospheric pressure plasma.The initial increase in the adhesion stress, higher for the low pressure plasma treatment than it was for the atmospheric pressure one, demonstrates the higher efficiency of the former.This enhanced efficiency is assigned to a higher density as well as a higher mean free path of the activated species in the low pressure plasma. Indeed, ions are still present in the low pressure plasma, whereas they tend to recombine quickly when exposed to the atmosphere for the atmospheric pressure plasma. The loss of such activated species could impinge on the chemical activity of the atmospheric pressure plasma treatment. 


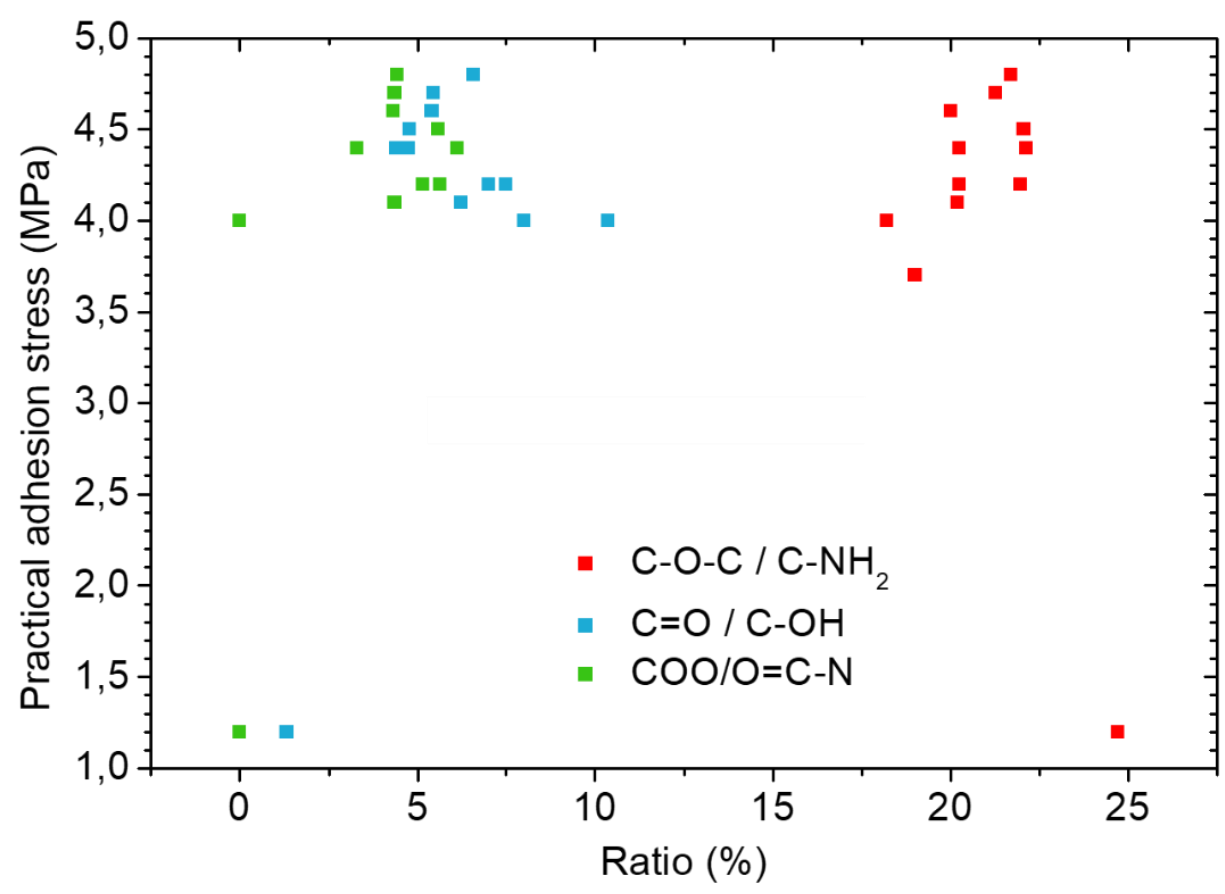

Figure 8 dependence of the practical adhesion stress on the ratio of the $C 1 s$ components.

The Figure 8shows, for all gas mixtures injected in the low pressure plasma chamber,that the practical adhesion stress increases from $1.2 \pm 0.4 \mathrm{MPa}$ for the untreated case to $4.8 \mathrm{MPa}$ for treated surfaces, when the $\mathrm{C}=\mathrm{O}$ and $\mathrm{COO}$ concentration increases(respectively from 1.9 to $10.4 \%$ and from 0 to $4.8 \%$ ). This increase in the practical adhesion stress is not supported by the C-O-C concentration, as itslightly decreases from 22.6 to $17.0 \%$. For the experimental conditions corresponding to a surface chemistry characterized by a higher proportion in surface hydroxyl, PEEK substrates showed lower practical adhesion stresses. This would indicate that formation of hydroxyl on the surface does not promote as much adhesion of metallic coatings. As for the atmospheric pressure, this observation shows that an increase in the polar groups induces an increase in the practical adhesion stress. Yet, the quick saturation of the functionalization does not allow a definitive analysis of the relationship between the adhesion stress and the functionalization of the surface. Nevertheless, both plasmas induce similar modifications of the surface chemistry, and its effect on the adhesion; the modification mechanisms of the surface thus seem to be independent on the plasma processes studied here. 
In this case however, the increase in the practical adhesion stress is observed with a clear decrease in the ether component from the untreated surface, meaning that this functional group has low or no effect on the adhesion properties. To visualize this correlation of the surface free energy and the practical adhesion to the proportions in the polar groups, 3D-contour plots of the results discussed above are shown.
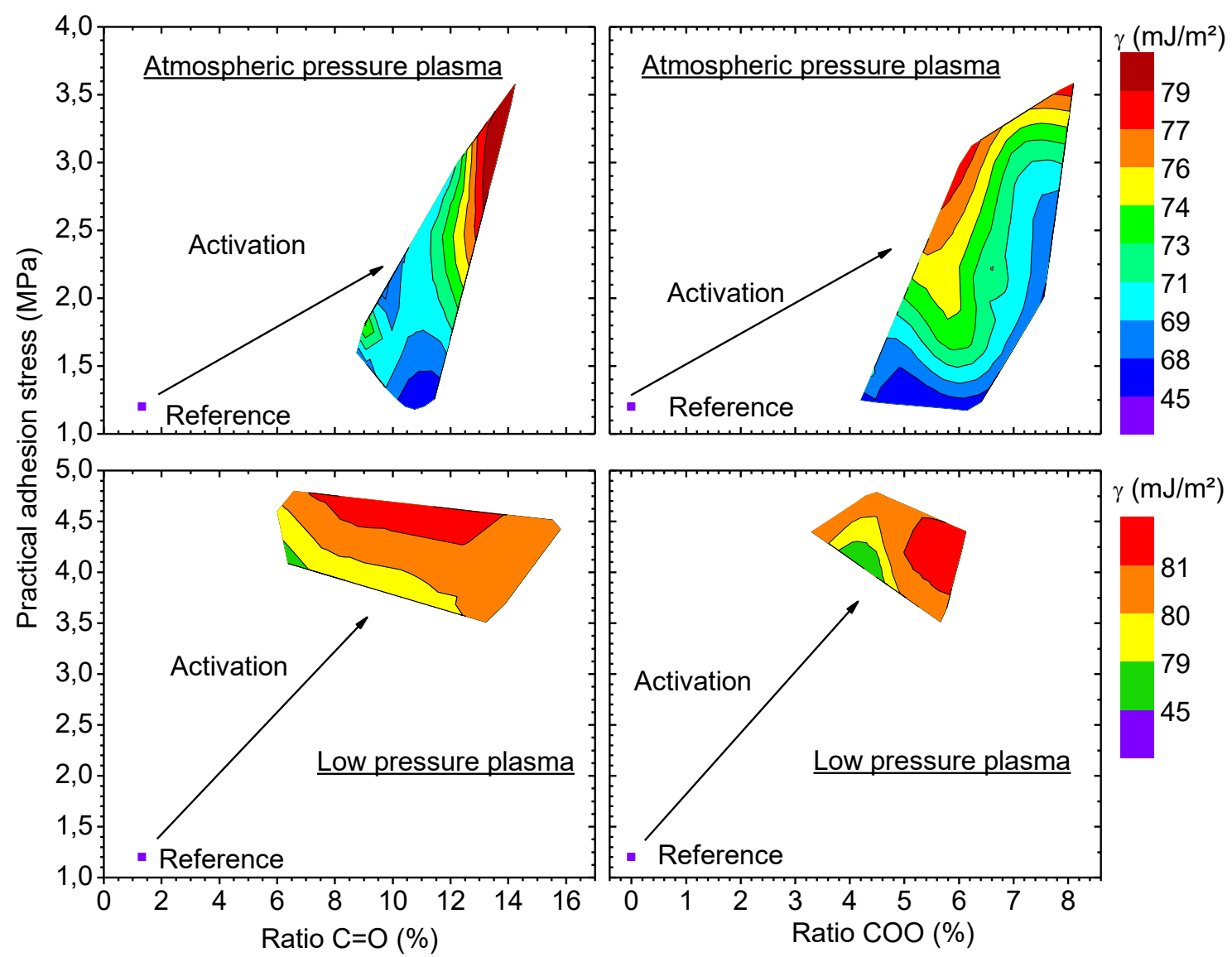

Figure 9 dependence of the practical adhesion stress (contour) and surface free energy (gradient spectrum) as a function of the proportion of surface $C=O$ and $C O O$ components (respectively left and right), for the atmospheric pressure plasma (top) and low pressure plasma (bottom).

The Figure 9shows a schematic synthesis of the evolution of the practical adhesion stress and surface free energy as a function of the $\mathrm{C} 1 \mathrm{~s}$ components, for both plasmas. This allows an easier representation of the correlation between the surface chemistry and the adhesion stress or the surface free energy, but also how the adhesion and surface energy are correlated. Every result of adhesion and surface chemistry measurements are plotted in the $X Y$ plane, while the 
corresponding surface free energy values are reported as a colour gradient inside the contour. This graph shows that the practical adhesion stress is directly proportional to the concentration of oxidized polar groups as represented by $\mathrm{C}=\mathrm{O}$ and $\mathrm{COO}$ bonds.Both plasma treatments studied induce a significant increase in the practical adhesion stress when the $\mathrm{C}=\mathrm{O}$ and $\mathrm{COO}$ ratiosreach a critical value of respectively 7 and $4 \%$. Beyond these critical ratios, increasing $\mathrm{C}=\mathrm{O}$ and $\mathrm{COO}$ components leads to enhance some more the adhesion stress. The increase in the adhesion stress, which is quicker in the case of the low pressure plasma, can be correlated to a parallel increase in the surface free energy of the PEEK substrate.

Yet, the curve profile is different between the two plasmas: the wider variations in the component proportions for the low pressure have been attributed to the richer, denser plasma in reactive particles, allowing a more complex surface chemistry. This functionalization, which is mainly characterized by the surface oxidization by addition of oxygenated polar groups, induces a quicker increase in surface free energy.However, this chemical effect is not sufficient to explain why the coating-substrate assemblies sustainhigher levels ofstressafter low pressure plasma-treatment than after atmospheric pressure plasma treatment. Indeed, the thermal shock occurring during atmospheric pressure plasma treatment may weaken the PEEK substrate and limits the maximum practical adhesion stress attainable, by inducing fracture in the material before interfacial separation. This cohesive fracture has been observed in our case when surfaces were treated by atmospheric plasma. Highest levels of adhesion, due to higher surface free energy levels, could be obtained by pre-heating the samples, thus limiting this thermal shock. It should be noted that for the treatment modes considered for both plasmas studied here, no significant increase of the surface roughness was observed. Indeed, atmospheric pressure plasma treated surfaces showed an arithmetic roughness $\left(R_{a}\right)$ of around $150 \mathrm{~nm}$, while low 
pressure plasma showed $R_{a}$ around $200 \mathrm{~nm}$. The increase in surface energy and practical adhesion is thus solely attributed to the chemical effect and not on the roughening of the surface.

\section{Conclusion}

We showed byXPS measurements that the plasma surface functionalization of PEEK induces a significant increase in the surface concentration of $\mathrm{C}=\mathrm{O}$ (ketone) and $\mathrm{COO}$ (ester/acid) functional groups, while C-O-C (ether) concentration remained relatively constant whatever the treatment applied to the polymer. A correlation between the concentration of the polar groups, i.e. $\mathrm{C}=\mathrm{O}$ and $\mathrm{COO}$ components, and the surface free energy and the practical adhesion stress was observed. Minimal values of $\mathrm{C}=\mathrm{O}$ and $\mathrm{COO}$ surface concentrations of respectively 7 and $4 \%$ are needed to efficiently enhance the wettability and the adhesion of aluminium coatings on PEEK substrates. Thus the practical adhesion stress increased up to a maximal value of 5 MPaandshowed a linear proportionality with the surface free energyfrom $60 \mathrm{~mJ} / \mathrm{m}^{2}$ to $81 \mathrm{~mJ} / \mathrm{m}^{2}$.Indeed, on the one hand, such functional polar groups are known to make bonds with metal atoms, which would induce an increase in the adhesion potential of the surface towards metallic coating. On the other hand, an increase in the surface polarity would increase the polar component of the surface free energy, significantly increasing the wettability of the surface.

While treatments with atmospheric and low pressure plasmas showed a similar behaviour on the correlation between surface chemistry and practical adhesion, differences in the functionalization process are still observed. First, the low pressure-plasma-treated surface is characterized by a higher concentration of polar groups which is attributed to a higher density in reactive gaseous species in the plasma phase.This higher reactivity furtherincreasesthe surface free energy and the adhesion potential. Second, a difference in the rupture modes of the 
coating-substrate assembly was observed between atmospheric and low pressure plasmas. This is explained in the case of atmospheric pressuretreatmentby the degradation of the mechanical properties of the PEEK substrate by thermal shock when exposed to the plasma. This was not observed for the low pressure plasma treatment, as the surface temperature increasedslower.

This study shows that to attain high levels of adhesion of metallic coatings on polymer substrates, surface functionalization conditions should be chosen to increase as much as possible the surface concentration of polar functional groups, while a careful consideration of the surface temperature during the treatment is needed to prevent the thermal degradation of the polymer substrate. This increase in the polarity of the surface would imply a significant enhancement of the surface wettability, and thus of the adhesion potential.

\section{References}

[1] C. Tendero, C. Tixier, P. Tristant, J. Desmaison, P. Leprince, Atmospheric pressure plasmas: A review, Spectrochim. Acta Part B At. Spectrosc. 61 (2006) 2-30. doi:10.1016/j.sab.2005.10.003.

[2] D. Rymuszka, K. Terpiłowski, P. Borowski, L. Holysz, Time-dependent changes of surface properties of polyether ether ketone caused by air plasma treatment, Polym. Int. 65 (2016) 827-834. doi:10.1002/pi.5141.

[3] T. Shao, C. Zhang, K. Long, D. Zhang, J. Wang, P. Yan, Y. Zhou, Surface modification of polyimide films using unipolar nanosecond-pulse DBD in atmospheric air, Appl. Surf. Sci. 256 (2010) 3888-3894. doi:10.1016/j.apsusc.2010.01.045.

[4] G.B. Rusu, I. Topala, C. Borcia, N. Dumitrascu, G. Borcia, Effects of AtmosphericPressure Plasma Treatment on the Processes Involved in Fabrics Dyeing, Plasma Chem. 
Plasma Process. 36 (2016) 341-354. doi:10.1007/s11090-015-9655-4.

[5] Y. Zhao, C. Zhang, X. Shao, Y. Wang, Y. Qiu, Effect of Atmospheric Plasma Treatment on Carbon Fiber/Epoxy Interfacial Adhesion, J. Adhes. Sci. Technol. 25 (2011) 28972908. doi:10.1163/016942411X576572.

[6] V. Prysiazhnyi, M. Stupavská, J. Ráhel’, C. Kleber, M. Černák, L.D. Rafailović, A comparison of chemical and atmospheric plasma assisted copper plating on carbon fiber reinforced epoxy polymer surfaces, Surf. Coatings Technol. 258 (2014) 1082-1089. doi:10.1016/j.surfcoat.2014.07.026.

[7] A. Dupuis, T.H. Ho, A. Fahs, A. Lafabrier, G. Louarn, J. Bacharouche, A. Airoudj, E. Aragon, J.-F. Chailan, Improving adhesion of powder coating on PEEK composite: Influence of atmospheric plasma parameters, Appl. Surf. Sci. 357 (2015) 1196-1204. doi:10.1016/j.apsusc.2015.09.148.

[8] D. Gravis, F. Poncin-Epaillard, J.-F. Coulon, Role of adsorbed water on PEEK surfaces prior to - and after - atmospheric plasma activation, Plasma Process. Polym. 15 (2018). doi:10.1002/ppap.201800007.

[9] D.K. Owens, R.C. Wendt, Estimation of the surface free energy of polymers, J. Appl. Polym. Sci. 13 (1969) 1741-1747. doi:10.1002/app.1969.070130815.

[10] J.F. Coulon, N. Tournerie, H. Maillard, Adhesion enhancement of Al coatings on carbon/epoxy composite surfaces by atmospheric plasma, Appl. Surf. Sci. 283 (2013) 843-850. doi:10.1016/j.apsusc.2013.07.028.

[11] S. Genty, J.-B. Sauvage, P. Tingaut, M. Aufray, Experimental and statistical study of three adherence tests for an epoxy-amine/aluminum alloy system: Pull-Off, Single Lap 
Joint and Three-Point Bending tests, Int. J. Adhes. Adhes. 79 (2017) 50-58. doi:10.1016/j.ijadhadh.2017.09.004.

[12] D. Briggs, G. Beamson, High Resolution XPS of Organic Polymers: The Scienta ESCA300 Database (Beamson, G.; Briggs, D.), J. Chem. Educ. 70 (1993) A25. doi:10.1021/ed070pA25.5.

[13] D.E. Packham, Surface energy, surface topography and adhesion, Int. J. Adhes. Adhes. 23 (2003) 437-448. doi:10.1016/S0143-7496(03)00068-X.

[14] C. Lambaré, P.-Y. Tessier, F. Poncin-Epaillard, D. Debarnot, Plasma functionalization and etching for enhancing metal adhesion onto polymeric substrates, RSC Adv. 5 (2015) 62348-62357. doi:10.1039/C5RA08844E.

[15] R. Nisticò, G. Magnacca, M.G. Faga, G. Gautier, D. D’Angelo, E. Ciancio, R. Lamberti, S. Martorana, Effect of atmospheric oxidative plasma treatments on polypropylenic fibers surface: Characterization and reaction mechanisms, Appl. Surf. Sci. 279 (2013) 285-292. doi:10.1016/j.apsusc.2013.04.087.

[16] D.P. Dowling, F.T. O’Neill, S.J. Langlais, V.J. Law, Influence of dc Pulsed Atmospheric Pressure Plasma Jet Processing Conditions on Polymer Activation, Plasma Process. Polym. 8 (2011) 718-727. doi:10.1002/ppap.201000145.

[17] M.J. Shenton, G.C. Stevens, Surface modification of polymer surfaces: atmospheric plasma versus vacuum plasma treatments, J. Phys. D. Appl. Phys. 34 (2001) 2761-2768. doi:10.1088/0022-3727/34/18/308.

[18] R.J. Good, Theory of "Cohesive" vs "Adhesive" Separation in an Adhering System, J. Adhes. 4 (1972) 133-154. doi:10.1080/00218467208072218. 
[19] M.-J. Wang, Y.-I. Chang, F. Poncin-Epaillard, Acid and basic functionalities of nitrogen and carbon dioxide plasma-treated polystyrene, Surf. Interface Anal. 37 (2005) 348-355. doi:10.1002/sia.2029.

[20] R.J.J. Jansen, H. van Bekkum, XPS of nitrogen-containing functional groups on activated carbon, Carbon N. Y. 33 (1995) 1021-1027. doi:10.1016/00086223(95)00030-H.

[21] N. De Geyter, R. Morent, C. Leys, L. Gengembre, E. Payen, Treatment of polymer films with a dielectric barrier discharge in air, helium and argon at medium pressure, Surf. Coatings Technol. 201 (2007) 7066-7075. doi:10.1016/j.surfcoat.2007.01.008.

[22] R. Morent, N. De Geyter, L. Gengembre, C. Leys, E. Payen, S. Van Vlierberghe, E. Schacht, Surface treatment of a polypropylene film with a nitrogen DBD at medium pressure, Eur. Phys. J. Appl. Phys. 43 (2008) 289-294. doi:10.1051/epjap:2008076. 


\section{TOC Graphic}

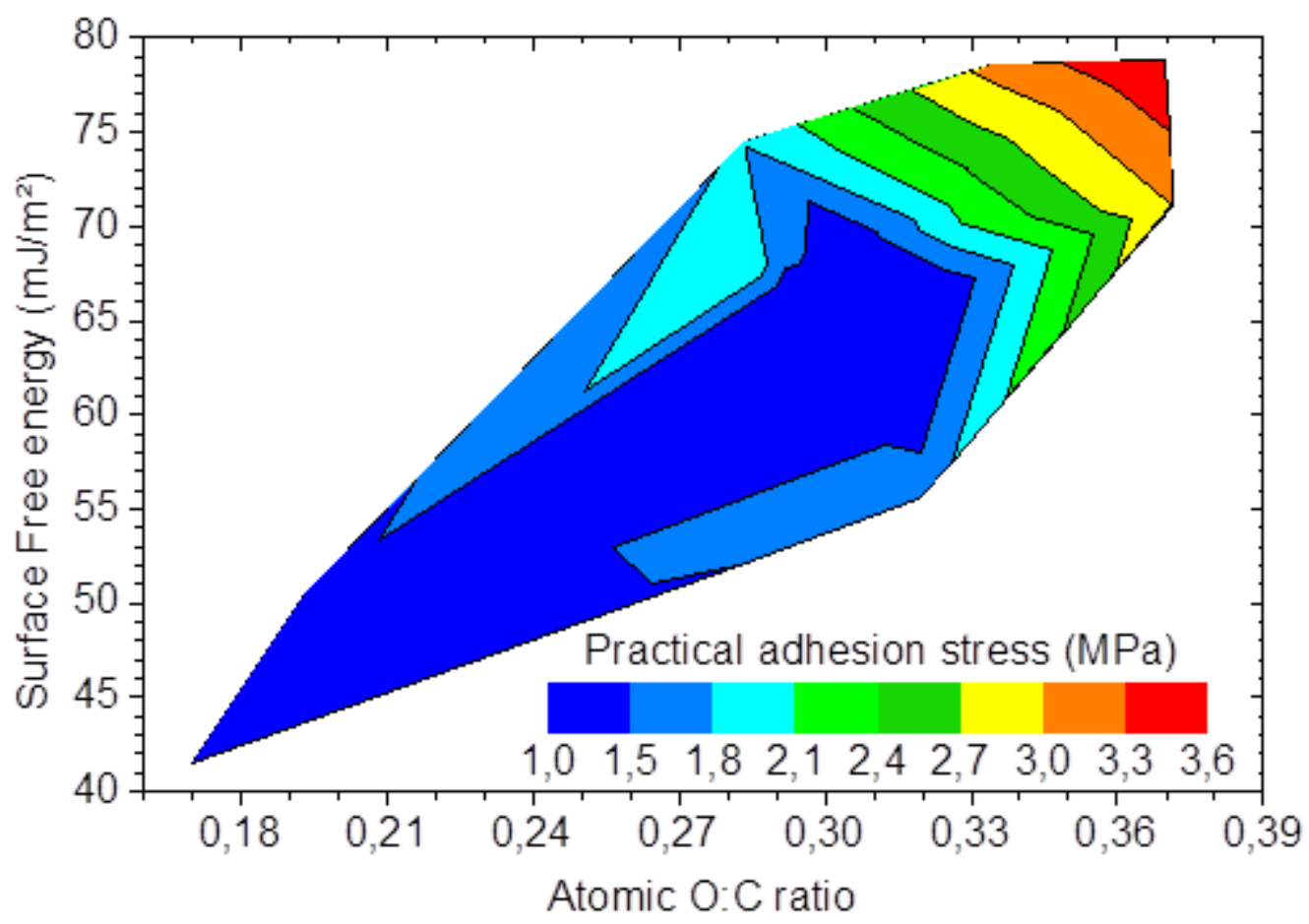

